\title{
Clinical Presentation and Histological Variation of Pleomorphic Adenoma of Salivary Glands
}

\author{
MNH KHANDKER ${ }^{\mathrm{a}}$, SMA SADAT $^{\mathrm{b}}, \mathrm{T}^{\mathrm{T}}$ RAHMAN $^{\mathrm{c}}$, IA HAIDER $^{\mathrm{d}}$, M AHMED $^{\mathrm{e}}$
}

Summary:

Background: Pleomorphic Adenoma is the most common salivary gland tumour accounts 40-70\% of all salivary gland tumour and about 60-80\% of the benign tumours and 60$70 \%$ of all parotid tumours. There is no study conducted in Bangladesh to observe the clinical and histological variation of the tumour. This study presents 36 cases of Pleomorphic adenoma collected over 11 months at the different territory hospital of Dhaka city.

Design: Observational study (November' 2011 to September' 2012)

Setting: Department of Oral and Maxillofacial Surgery (Dhaka Dental College and Hospital, Bangabandhu Sheikh Mujib Medical Universityl), Department of ENT and HeadNeck Surgery (Dhaka Medical College and Hospital, Bangabandhu Sheikh Mujib Medical University).

Method: The entire patient clinically and cytologically diagnosed as Pleomorphic adenoma were selected. Data were collected in a summarized data sheet. Then histopathological types of them were analyzed from excisional biopsized tissue.

Result: There were 36 patients of Pleomorphic adenoma of which 24(66.67\%) in Parotid glands, 4(11.11\%) in

a. Dr. Md. Nazmul Hasan Khandker, Assistant Professor,Dept of Dental \& Facio-maxillary Surgical Oncology, National Institute of Cancer Research and Hospital (NICRH), Mohakhali, Dhaka

b. Dr. S. M. Anwar Sadat,Associate Professor and Head of the Dept, Oral and Maxillofacial Surgery, Dental Unit, Sher-e-Bangla Medical College, Barisal.

c. Dr. Tarin Rahman,Associate Professor, Dept of Oral and Maxillofacial Surgery,Dhaka Dental College and Hospital,Dhaka.

d. Prof. Dr. Ismat Ara Haider, Professor \& Head of the Dept, Oral and Maxillofacial Surgery, Dhaka Dental College and Hospital, Dhaka.

e. Prof. Dr. Mohiuddin Ahmed, Principal, Sapporo Dental college and Hospital, Dhaka.

Address of Correspondence: Dr. Md. Nazmul Hasan Khandker, Assistant Professor,Dept of Dental \& Facio-maxillary Surgical Oncology, National Institute of Cancer Research and Hospital (NICRH), Mohakhali, Dhaka. Cell phone:+8801712213311 Email:nazmul34@yahoo.com

Received: 8 May, 2018

Accepted:25 February, 2019
Submandibular glands and $8(22.22 \%)$ in minor salivary glands. Among the respondents, female was predominant $20(55.56 \%)$ with ages were between 29 years to 65 years old (mean age $44.83 \pm 8.32$ years) with most patients (44.44\%) in 41 to 50 years of life. In histophathological study showed Stromal rich $38.89 \%$, cell rich $36.11 \%$ and classic $25 \%$. Cuboidal cells were the most commonly found cellular type followed by plasmacytoid and spindle.Trabeculae and duct like structures were the most frequent pattern by the epithelial cells. Myxoid and Hyalinization were the most frequently found mesenchymal like tissue.Cases presented with symptoms such as swelling (100\%), limitation of mouth opening, paesthesia and pain.

Conclusion: The knowledge about clinical presentation and the immense variety of cells, architectures and morphological characteristics present in Pleomorphic adenoma of the salivary gland is essential for correct diagnosis and prognosis. The need for improved diagnostic facilities and upgrading of infrastructure was stressed.

Key words: Pleomorphic adenoma, Salivary gland, Parotid gland, Benign tumor

(J Bangladesh Coll Phys Surg 2019; 37: 72-77)

DOI: https://doi.org/10.3329/jbcps.v37i2.40563

Introduction:

Salivary gland tumours are rare. Comprising less than $3 \%$ of all neoplasms of the Head and neck region ${ }^{1}$ .Pleomorphic Adenoma is defined by WHO as "a circumscribed tumour characterized by its pleomorphic or mixed appearance clearly recognizable epithelial tissue being intermingled with tissue of mucoid,myxoid and chondroid appearance".

Pleomorphic adenoma is a benign mixed tumour of the salivary gland which shows a remarkable degree of morphological diversity. It is the most common tumour of the salivary gland, accounting for approximately $40 \%$ to $70 \%$ of all salivary gland tumours ${ }^{2}$.It accounts for about $60 \%$ to $80 \%$ of the benign tumours of salivary glands and for $60 \%$ to $70 \%$ of all parotid tumours . It is less commonly 
seen in submandibular solivary gland (10\%), in sublingual gland $(1 \%)$,in minor salivary glands $(5 \%-10 \%)^{3}$.

Pleomorphic adenoma occurs at any ages but the highest incidence is in the fourth to sixth decade of life $\mathrm{e}^{4}$. There is slight predominance among females than males .

Pleomprtphic adenoma clinically presents as a mobile slowly growing, painless firm, clearly demarcated mass that does not cause ulceration of the overlying mucosa ${ }^{5}$.In parotid $90 \%$ occurs in the superficial lobe and most commonly are seen in the tail of the gland . Pleomorphic Adenoma in deep lobe of parotid gland may present as an oral retrotonsillar mass or parapharyngeal space tumour. In the minor salivary glands the most frequent site of involvement is the region of the hard palate followed by upper lip, buccal mucosa, floor of the mouth. Rare and unusual site of occurrence include ectopic salivary gland tissue (mandible, neck lymph node, axilla) ${ }^{6}$.In all locations they are typically non tender to palpation and tend to be mobile when small but may fixed with advanced growth. In minor salivary glands it usually presents as slow growing submucosal mass that does not cause ulceration of the overlying mucosa ${ }^{7}$. Facial nerve paralysis in association with pleomorphic adenoma all most never occurs even with extremely large tumours but facial nerve involvement is likely to arise as a result of malignant change .

Microscopically the tumour composed of epithelial and myoepithelial cells arranged in a great variety of morphological patterns with areas of masenchymal differentiation ${ }^{8}$. Histologically the tumour is consisting of an epithelial component such as plasmacytoid, spindle, clear, squamous, basaloid, cubic, oncocytoid, mucous cell that form morphologic pattern are trabecular, ductal, cystic, solid. The stromal components are myxoid, chondroid, hyaline, calcified tissue. The total tumour may be myxoid or stroma rich,cellular or cell rich and classic (balanced amount of epithelial and stromal component ${ }^{9}$.It shows remarkable degree of morphological diversity .According to relative proportion between the stromal and epithelial components of pleonorphic adenoma it classified as 1)stroma accounts for $30-50 \%$ of the tumour.2) stroma accounts for more than $80 \%$ of the tumour.3)stroma accounts for less than 30\%.4)stroma accounts for less than $30 \%$ but is predominantly made up of a monomorphic epithelial cellular component of plasmacytoid or hyaline appearance ${ }^{10}$.

Regarding histological variation United States, United Kingdom, South Africa, Australia, Germany, Mexico have done a lot of study. In South Asia few study and scattered case reports are published.

In Bangladesh there was no study conducted to observe the clinical presentation and histological variations of pleomorphic adenoma of salivary gland.It is evident that no reports on clinical presentation and histologic variation has been published in Bangladesh and there is absence of series studies. This study included patient attended to different territory hospitals of Dhaka city over a limited period of time which would help for clarification and better understanding about the diversity of this tumour

\section{Materials and Methods:}

The Observational study was carried out in the Department of Oral and Maxillofacial Surgery (Dhaka Dental College and Hospital, Bangabandhu Sheikh Mujib Medical University), Department of ENT and Head-Neck Surgery (Dhaka Medical College and Hospital, Bangabandhu Sheikh Mujib Medical University )from November'2011 to September' 2012.

Sampling technique: Convenient sampling.No formula was followed.Due to rarity of the disease only 36 cases were enrolled in the study.

Participants: All the patients with Pleomorphic Adenoma were irrespective of age and sex were selected for the study. Sample size of the study was 36 , of them 16 were male and 20 cases were female.

Method: The entire patient clinically and cytologically diagnosed as Pleomorphic adenoma were selected. Data were collected in a summarized data sheet. Then histopathological types of them were analyzed from excisional biopsized tissue. 


\section{Results:}

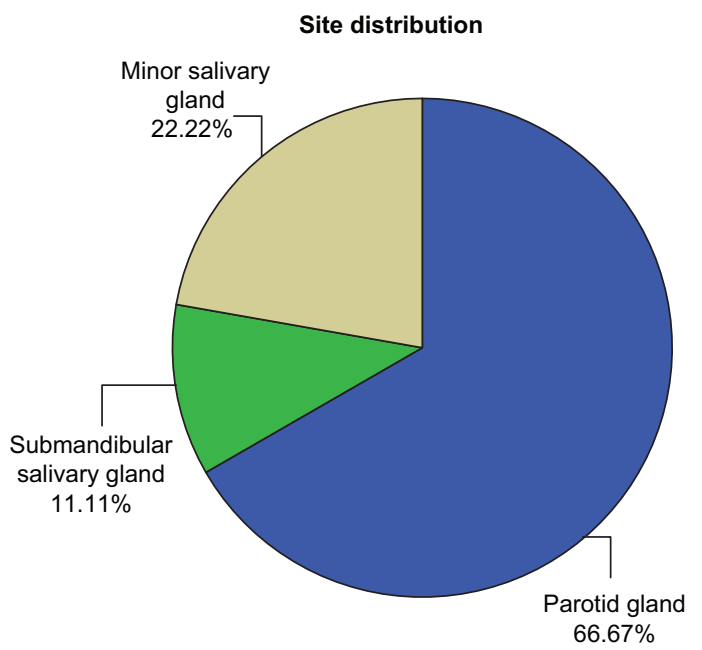

Fig.-1: Site Distribution of Pleomorphic Adenoma

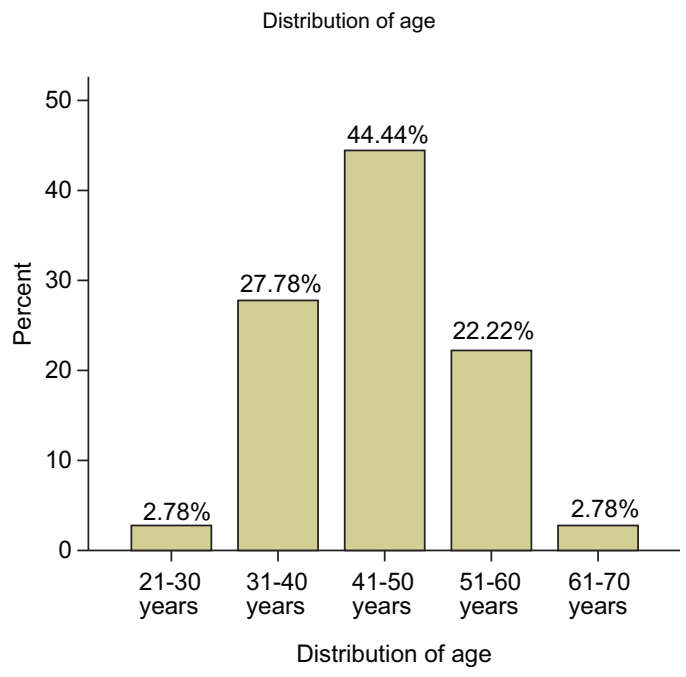

Fig.-2: Distribution of the respondents by Age

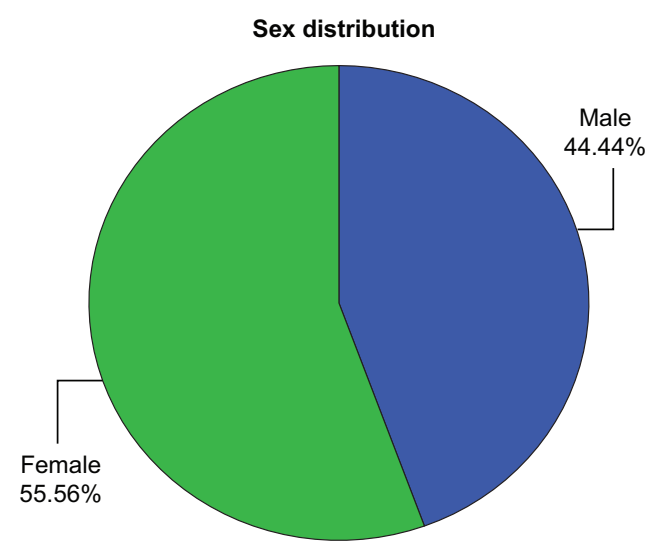

Fig.-3: Distribution of the respondents by Sex
Distribution (\%) of respondents by clinical features

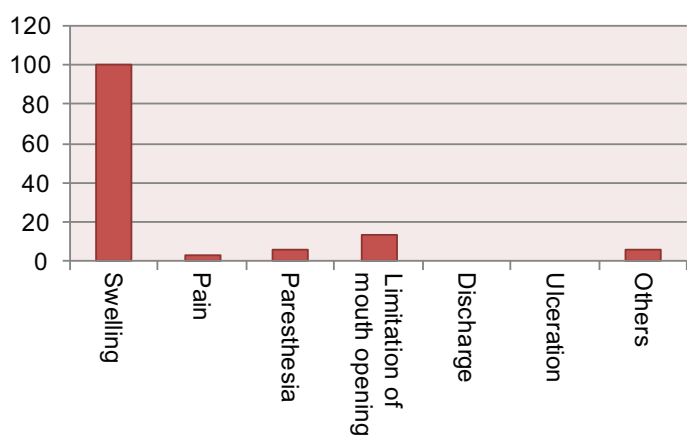

Fig.-4: Distribution of the respondents by clinical features

\section{Table-I}

Distribution of the respondents by State of the tumour

\begin{tabular}{lcc} 
State of the tumour & Frequency & Percent \\
\hline Primary & 34 & 94.4 \\
Recurrance & 2 & 5.6 \\
\hline
\end{tabular}

Histological classification

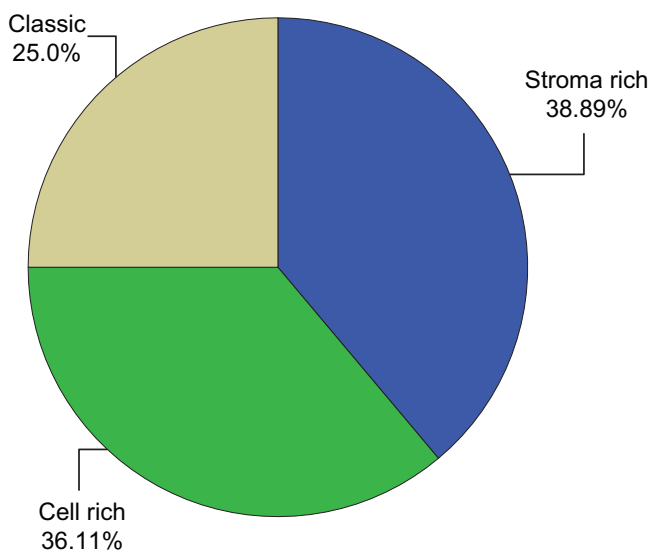

Fig.-5: Histological Variations of plasmorphic adenoma.

Table-II

Histological type in relation to sex

\begin{tabular}{lcc} 
Histological classification & \multicolumn{2}{c}{ Sex distribution } \\
\cline { 2 - 3 } & Male & Female \\
\hline Stroma rich & $8(57.1 \%)$ & $6(42.9 \%)$ \\
Cell rich & $5(38.5 \%)$ & $8(61.5 \%)$ \\
Classic & $3(33.3 \%)$ & $6(66.7 \%)$ \\
\hline
\end{tabular}


Table-III

\begin{tabular}{lcccccccc}
\hline & \multicolumn{7}{c}{ Tumour cellsCells of the epithelial component } \\
\cline { 2 - 8 } & Plasmacytoid & Spindle & Cuboidal & Basaloid & Squamous & Clear & Mucous & Oncocytic \\
\hline Absent $\mathrm{n}(\%)$ & $2(5.6)$ & $2(5.6)$ & 0 & $32(88.9)$ & $23(63.9)$ & $36(100)$ & $36(100)$ & $36(100)$ \\
$<30 \% \mathrm{n}(\%)$ & $24(66.7)$ & $27(75)$ & $7(19.4)$ & $3(8.3)$ & $13(36.1)$ & 0 & 0 & 0 \\
$31-50 \% \mathrm{n}(\%)$ & $5(13.9)$ & $7(19.4)$ & $7(19.4)$ & 0 & 0 & 0 & 0 & 0 \\
$>51 \% \mathrm{n}(\%)$ & $5(13.9)$ & 0 & $22(61.1)$ & $1(2.8)$ & 0 & 0 & 0 & 0 \\
\hline
\end{tabular}

Table-IV

\begin{tabular}{|c|c|c|c|c|c|c|c|c|c|}
\hline & \multirow[b]{2}{*}{ Trabeculae } & \multicolumn{3}{|c|}{ Epithelial component } & \multicolumn{5}{|c|}{ Stromal Component } \\
\hline & & Ducts & Cysts & Solid & Myxoid & Chondroid & Hyalinization & Calcification & Fibrous \\
\hline Stroma-richn( $\%)$ & $14(100)$ & $13(92.9)$ & $9(64.3)$ & $13(92.9)$ & $14(100)$ & 11(78.6) & $13(92.9)$ & $3(21.4)$ & $1(7.1)$ \\
\hline Cell-rich n(\%) & $13(100)$ & $12(92.3)$ & $9(69.2)$ & $12(92.3)$ & 11(84.6) & $9(69.2)$ & 11(84.6) & $3(23.1)$ & $5(38.5)$ \\
\hline Classicn $(\%)$ & $9(100)$ & $9(100)$ & $8(88.9)$ & $9(100)$ & $9(100)$ & $8(88.9)$ & $8(88.9)$ & $1(11.1)$ & $2 .(22.2)$ \\
\hline
\end{tabular}

\section{Discussion:}

Pleomorphic adenoma is a slow growing salivary gland tumor most commonly arising in Parotid gland. It accounts for $60 \%$ to $73 \%$ of the parotid gland tumors, $40 \%$ to $60 \%$ of the sub mandibular and minor salivary glands ${ }^{11}$.This cross-sectional observational study on Clinical presentation and Histological variation of Pleomorphic adenoma of salivary glands in different territory hospital of Dhaka city over a period of 11 months (November 2011 to September 2012) on 36 patients of Pleomorphic adenoma, among them 24 $(66.67 \%)$ were found in parotid gland, $4(11.11 \%)$ were found in submandibular gland and $8(22.22 \%)$ were found in minor salivary glands, no tumor was found in Sublingual salivary gland which is near to similar to other study ${ }^{9}$. Mejia-Velazquer CP et al ${ }^{12}$, reported 360 cases in which $76.7 \%$ found in parotid gland and 1 case identified in sublingual salivary gland. In the registry of Armed forces institute of pathology of 6880 cases of Pleomorphic adenoma records only 126 cases affecting minor salivary glands of cheek (1.8\%). Chidzonga MM et $\mathrm{al}^{13}$ studied the Clinico Pathological study of 206 cases of Pleomorphic adenoma in Zimbabwe showed 39.8\% Pleomorphic adenoma in Parotid gland.

In this study, female represent $(55.56 \%)$ and male represent (44.44\%) which is similar to the most other study and most commonly found at the age of $3^{\text {rd }}$ to $6^{\text {th }}$ decades with a mean age of $44.83 \pm 8.32$. The peak incidence is $4^{\text {th }}$ to $5^{\text {th }}$ decades. Mejia-velazquez, cp et $\mathrm{al}^{12}$, and Ito FA et $\mathrm{al}^{9}$ showed similar age and sex incidence. Yamamato $\mathrm{H}$ et $\mathrm{al}^{20}$ reported a 9 years old Japanese girl with Pleomorphic adenoma of cheek mucosa. Dhanuthai $\mathrm{K}$ et $\mathrm{al}^{14}$ reported the first case of palatal Pleomorphic adenoma in a 13 years old child. Jorge et $\mathrm{al}^{21}$ reportd 5 cases of intraoral Pleomorphic adenoma in patients under 18 years of age in two Brazilian institution.

In this study on 36 patients, main clinical features were encountered swelling (100\%), Pain (2.8\%), limitation of mouth opening (13.9\%) and paresthesia (5.6\%). No ulceration or discharge or sinus were found among the patients. In this study paresthesia were found in two recurrent cases and this paresthesia may be due to previous surgical intervention. pain was reported in a very large tumor manipulated by previous FNAC or clinical examination. Other clinical features were found such as difficulty in mastications and speech in a very large Pleomorphic adenoma located on palate. One cases showed discolouration of overlying skin due to application of Aurbedic drugs.In minor salivary glands, Pleomorphic adenoma presents as slow growing submucosal mass, the covering mucosa was 
intact which was similar to other study .This variation in clinical features may be due to smaller sample size of this study.

In this study 34 (94.4\%) tumor were primary and $2(5.6 \%)$ were recurrent, which is more or less similar to other study. Enucleation instead of parotidectomy is the risk factor for recurrence. Presence of pseudocapsule is attributed to recurrence .Rupture of the capsule and tumour spillage in the wound is believed to increase the risk of recurrence.

Regardless of the great variety of histopathological aspects the main diagnostic feature is the presence of both epithelial and mesenchymal like tissue.The proportion of these tissue has been used to sub-classify Pleomorphic adenoma. This study showed stroma riched sub-type in 14 (38.9\%) cases, cell rich subtypes in $13(36.1 \%)$ cases and classic sub-type in $9(25 \%)$ cases. In stroma rich varient predominant in male(57.1\%), Cell rich variant predominent in female $(61.5 \%)$ and classic variant predominant in female(66.7\%), which is interestingly close to those reported by Sternert et $\mathrm{al}^{15}$ and Paris et $\mathrm{al}^{16}$. Ito FA et $\mathrm{al}^{9}$ studied 189 pleomorphic adenoma and reported stroma riched in $99(52.4 \%)$ cases, cell riched in $69(36.5 \%)$ cases and classic in $21(11.1 \%)$ cases. This study slightly dissimilar to the present study probably due to smaller sample size and a limited period of time.

Regarding epithelial cell types, this study showed cuboidal cells were the most frequent cell type(100\%) They represent less than $30 \%$ of the tumour cells in $19.4 \%$ cases, 31 to $50 \%$ in $19.4 \%$ cases and more than $51 \%$ in $61.1 \%$ cases. plasmacytoid cells represent the $2^{\text {nd }}$ frequent cell type and present in $94.44 \%$ cases. They represent less than $30 \%$ of the tumour cells in $67.7 \%$ cases, 31 to $50 \%$ in $13.9 \%$ cases and more than $51 \%$ in $13.9 \%$ cases. Spindle cells represent $3^{\text {rd }}$ frequent cell type and followed by squamous and then Basaloid cell type. Clear, mucous, oncocytic cells were occasionally present. Ito FA et $\mathrm{al}^{9}$ studied in Londrina Cancer Institute Brazil from 1972 to 2001 \& dealed with 496 salivary gland tumours, 189 of that were pleomorphic adenoma \& reported Histologically that plasmacytoid cells were the most commonly found celluler type present in all studied tumours. Spindle cell were the second most frequent cellular type, cuboidal cells were the $3^{\text {rd }}$ frequent cell followed by Basaloid cells, squamous, clear cell.Mucous found. 6 cases $(2.6 \%)$ they found focal cellular atypia, nonrelated to infarcted tissue, 5 cases $(2.52 \%)$ shows demonstrated infraction with necrosis. One cases presented pigmented cells. et al (1999 p.993-9) reported same histological findings.

Concerning morphological pattern, trabeculae formation found in $100 \%$ cases. duct formation in $94.44 \%$ cases, cysts formation in $72.2 \%$ cases, solid in $94.4 \%$ cases. Every components predominently found in stroma riched variant than cell riched and classic varrient. Ito $\mathrm{FA}$ et $\mathrm{al}^{9}$ reported trabecule and duct formation predominantly found in stroma riched varrient but cyst formation predominantly found in cell riched varrient.

Concerning stromal component, myxoid stromal component was present in 34(94.44\%) cases, chondroid in $28(77.74 \%)$ cases, hyalinization in $32(88.9 \%)$ cases. Calcification in $7(19.4 \%)$, Fibrous Component in $8(22.2)$ cases. Ito $\mathrm{FA}$ et $\mathrm{al}^{9}$ reported more or less similar result.

Seifert et $\mathrm{al}^{10}$ subclassified pleomorphic adenoma into four subtypes according to relative proportion of stroma and cellular components.i) stroma accounts for $30 \%$ to $50 \%$ of the tumour.ii) stroma accounts for more than $80 \%$.iii) stroma accounts for less than $30 \%$,iv) stroma accounts for less than $30 \%$ but is predominantly made up of a monomorphic epithelial cellular component of plasmacytoid or hyaline appearance. Margaritscu CL at al ${ }^{17}, 1$ studied 103 cases of pleomorphic adenoma and found that more than $55 \%$ cases were stroma rich of that type i) and type ii) were predominant. In epithelial proliferation had trabecular and tubular patterns with predominantly myxoid and chondroid stroma.

Microscopic findings like necrosis, nuclear atypia, invasion of adjacent tissue, abnormal mitotic figure are features of aggressive behavior of malignant transformation reported by Auclair et al ${ }^{18}$. These features are not present in this present study. Hyalinization which is also a feature of abnormal behavior or malignant transformation, as described by Auclair et $\mathrm{al}^{18}$, found in this present study.

In this study no foci of squamous metaplasia with extensive keranization has found which was reported 
by Irving Dardick et $\mathrm{al}^{19}$, there is no report about the characteristics of capsule. Thinness of capsule was significantly related to hypocellularity. Capsule infiltration is not correlated with malignant transformation but may play a role in the recurrence of pleomorphic adenoma.

Especially in developing countries like Bangladesh poverty, ignorance about medical problems and poorly developed medical infrastructure contribute to morbidity and mortality from various diseases. As pleomorphic adenoma is painless, slow growing tumour patient is not aware to take appropriate treatment at early stage. Adequate skilled doctors with treatment facility is needed for proper management. Although FNAC is fairly accurate for diagnosis of pleomorphic adenoma but this may be misdiagnosed in absence of expertise. While patient management is improved with adequate diagnostic and treatment facilities, healthcare must be accessible to the population for their benefit.

\section{Conclusion:}

In the department of Oral \& Maxillofacial Surgery (Dhaka Dental College Hospital, Bangabandhu Sheik Mujib Medical University), department of ENT \& Head-Neck Surgery (Dhaka Medical College Hospital, Bangabandhu Sheikh Mujib Medical University), accounts for 36 pleomorphic adenoma patient, mostly present in parotid gland (66.67\%), with female predominance. Most of the affected people were in $3^{\text {rd }}$ to $6^{\text {th }}$ decade with highest incidence at $4^{\text {th }}$ to $5^{\text {th }}$ decades of life. The tumours were predominantly stroma riched (38.9\%), cell.riched (36.1\%) and classic type $(25 \%)$. They need for improved diagnostic facilities and upgrading of infrastructure were strongly felt.

\section{References:}

1. Vander Wal JE, Leverstein H, Snow GB, Kraaijenhagen HA, Van der Waal I. Parotid gland tumors:histologic reevaluation and re classification of 478 cases.Head Neck.1998;20:204-7.

2. Matturri,L.,Lavezzi, A.M.,Biondo, B. \& Mantovani, M. Cell kinetics of pleomorphic adenomas of the parotid gland.Eur.J.cancer B,Oral Oncol.1996;32b:154-7.

3. Silva SJ,Costa GT,Filbo ACB, Faria PR, Loyola AM. Metachronous bilateral pleomorphic adenoma of the parotid gland.Oral surgery, Oral medicine, Oral pathology, radiology \&Endodontology.2006;101(3):333-338.

4. Aver-De-Araujo LM, Chaves-Tarquinio SB, Neuzling-Gomes AP, Etges A. Intraosspous pleomorphic adenoma:case report and review of the literature.Med Oral.2002;7:164-70.
5. Dalati T, Hussein MR. Juvenile Pleomorphic adenoma of the cheek:a case report and review of literature. Diagnostic pathology.2009;4(32):1-5.

6. Kondo T: A case of lipomatous pleomorphic adenoma in the parotid gland.Diagn pathol.2009;4:16.

7. Kaminski M, Janicki K: A case of giant pleomorphic adenoma of the cheek with two malignant centers. otolaryngol pol.2002; 56:385-7.

8. Ellias GL, Auclair PL. Tumors of salivary glands(Atlas of tumor pathology) $3^{\text {rd }}$ series.fascicle 17. Washington,DC: Armed forces of institute of pathology:1996.

9. Ito FA, Jorge J, Vargas PA, Lopes MA. Histological findings of pleomorphic adenomas of salivary glands. Med oral patol Oral Cir Buccal . 2009 Jan1 ;14(2):E57-61.

10. Seifert G, Rieb H, Donath K. Classification der tumoren der kleinen speichel-drusen:patho-histologishe analyse von 160 tumoren. laryngorhinootologie.1980;59:379-400.

11. Ito FA, Ito K, Vargas PA, De Almeida OP, Lopes MA. Salivary gland tumours in a Brazilian population: a retrospective study of 496 cases. International Journal of Oral and Maxillofac Surg. 2005;34:533-6.

12. Mejia-Velazquez CP, Duran-Padilla MA, Gomez-Apo E, Quezada-Rivera D, Gaitan-Cepeda LA. Tumors of the salivary gland in Mexicans. A re-trospective study of 360 cases. Med Oral Patol Oral Cir Bucal2012 Mar 1;17(2):183-9.

13. Chidzonga MM, Lopes Perez VM, Portilla Alvarez AL. Pleomorphic adenoma of the salivary glands:clinicopathologic study of 206 cases in Zimbabwe.Oral surg Oral med Oral pathol Oral radiol Endod. 1995;79:747-9.

14. Dhanuthai K, Sappayatosok K, Kongin K. Pleomorphin adenoma of the palate in a child: a case report. Med Oral Patol Oral Cir Bucal.2009;14;E 73-5.

15. Stennert E, Guntinas-Lichius O, Klussmann JP, Arnold G. histopathology of pleomorphic adenoma in the parotid gland: a prospective unselected series of 100 cases. Laryngoscope 2001;111:2195-200.

16. Paris J, Facon F, Chrestian MA, Giovanni A, Zanaret M. Pleomorphic adenoma of the parotid: histopathological study. Ann Otolaryngol chir Cervicofac. 2004;121:161-6.

17. Margaritescu C, Raica, M, Simionescu C, Mogoalta L, Surpateanu M, Jaubert F, et al. Tumoral stroma of salivary pleomorphic adenoma -histopathological, histochemical and immunohistochemical study. Rom J Morphol Embryol 2005; 46:211-23.

18. Auclair PL, Ellis GL. Atypical features in salivary glands mixed tumours: their relationship to the malignant transformation. Mod Pathol. 1996;9:652-7.

19. Dardick I, Birek C, Lingen MW, Rowe PE. Differentiation and the cytomorphology of salivary gland tumours with spefic reference oncocytometaplasia.Oral surg Oral med Oral pathol oral radiol Endod. 1999;88:691-701.

20. Yamamoto H, Fukumoto M, Yamaguthi F, Sakata k, Oikawa T: Pleomorphic adenoma of the buccal gland in a child. Int J Oral Maxillofac Surg. 1986;15:474-7.

21. Jorge J, Pires FR, Alves FA, Perez DE, Kowalski LP, Lopes MA, Almeila OP: Juvenile Intra Oral pleomorphic adenoma: report of five cases and review of the literature. Int J Oral Maxillofac Surg. 2002;31:273-5. 